\title{
Do stars govern our actions? Astrocyte involvement in rodent behavior
}

\author{
João Filipe Oliveira, ${ }^{1,2}$, Vanessa Morais Sardinha ${ }^{1,2}$, Sónia Guerra-Gomes ${ }^{1,2}$, \\ Alfonso Araque ${ }^{3}$, and Nuno Sousa ${ }^{1,2}$ \\ ${ }^{1}$ Life and Health Sciences Research Institute (ICVS), School of Health Sciences, University of Minho, $4710-057$ Braga, Portugal \\ ${ }^{2}$ ICVS/3B's - PT Government Associate Laboratory, Braga/Guimarães, Portugal \\ ${ }^{3}$ Department of Neuroscience, University of Minnesota, Minneapolis, MN 55455, USA
}

\begin{abstract}
Astrocytes have emerged as important partners of neurons in information processing. Important progress has been made in the past two decades in understanding the role of astrocytes in the generation of neuronastrocyte network outputs resulting in behavior. We review evidence for astrocyte involvement across four different behavioral domains: cognition, emotion, motor, and sensory processing. Accumulating evidence from animal models has provided a wealth of data that largely supports a direct involvement of astrocytes on diverse aspects of behavior. The development of tools for selectively controlling the temporal and spatial properties of astrocyte activity will help to consolidate our knowledge of the mechanisms underlying this involvement.
\end{abstract}

The neuron-astrocyte interaction $\mathbf{2 5}$ years later

The ability to understand astrocyte activity by recording and quantifying calcium dynamics in astrocytes using imaging techniques has allowed the elucidation of the functional properties of astrocytes in the brain [1-3]. These seminal studies prompted neuroscientists to acknowledge the active features of astrocytes, and triggered their curiosity to understand the level of interaction that these cells would maintain with neurons under physiological conditions. Since these pioneering efforts, numerous studies have pointed out five main features of astrocytes: (i) they play relevant roles in brain homeostasis, contributing to the blood-brain barrier and maintaining extracellular levels of ions and neurotransmitters; (ii) they are in close physical contact with synapses and neurons, other glial cells, and vascular structures in the brain; (iii) they express several functional neurotransmitter receptors (e.g., those for glutamate, ATP, GABA, acetylcholine, or endocannabinoids) which allow them to sense surrounding neuronal activity; (iv) they show intracellular calcium-based excitability with complex temporal and spatial properties and may trigger paracrine signaling to neighboring astrocytes; (v) they are able to release neuro- and vasoactive substances, such as glutamate, D-serine, ATP, GABA, tumor

Corresponding author: Oliveira, J.F. (joaooliveira@ecsaude.uminho.pt).

Keywords: astrocyte; behavior; cognition; emotion; motor; sensorial.

0166-2236/

(C) 2015 Elsevier Ltd. All rights reserved. http://dx.doi.org/10.1016/j.tins.2015.07.006 necrosis factor $\alpha(\mathrm{TNF}-\alpha)$, prostaglandins, or peptides, in a process known as gliotransmission which can lead to the modulation of synaptic function, blood flow, and metabolism (see [4-13] for detailed reviews]. These features underlie the dynamic interaction between astrocytes and neurons that complements and modulates the communication between pre- and postsynaptic structures, a concept termed the tripartite synapse $[12,14]$. In the tripartite synapse, astrocytes respond to surrounding synaptic activity with calcium signaling, which in turn cause feedback regulation of neuronal activity and synaptic strength through gliotransmitter release. Regarding the mechanism of the tripartite synapse, it was recently proposed that astrocytes incorporate information shared inside and outside synapses, and process signals in a scaled manner, but within temporal and spatial dimensions that differ from those of neurons. This view unifies the hundreds of observations published in the past two decades of intensive research in this field [5].

While important progress has been made in defining the modulatory role of astrocytes in synaptic transmission, and in identifying the underlying cellular mechanisms, fundamental aspects of the consequences of the functional interaction of astrocytes and neurons on information processing at higher organization levels, in other words neural networks and animal behavior, have only more recently begun to be explored. A major challenge for studying the role of astrocytes in information processing and behavior stems from the suitability of available approaches to specifically target astrocyte function and reliably measure the consequences on network output in vivo. Therefore, the main goal of this review is to compile evidence of the importance of neuron-astrocyte network outputs on the behavior of animal models in which astrocytes have been targeted specifically by pharmacological and/or genetic manipulation. While excellent recent reviews have focused on specific related topics, such as the role of glia in cognitive function [15], astrocyte and neuron-astrocyte networks $[10,16]$, the complexity of astrocyte activation and calcium signaling [17-20], purinergic signaling and behavior [21], molecular approaches for in vivo studies [22-25], and astrocyte contributions to pathophysiological processes [6,26-30], we aim here to review and discuss the different in vivo evidence that indicates the involvement of astrocytes in animal behavior. 


\section{Animal models to study astrocyte function in vivo}

The study of astrocyte function in vivo is a daunting task owing to the difficulty of dissecting out the astrocytic component from the output of the neuron-astrocyte network. Neuroscientists have tried to overcome this difficulty by taking advantage of specific pharmacological and/or genetic tools that either reduce or enhance astrocyte functions in animal models, mostly in rodents. Table 1 summarizes a list of the animal models that have been used to study astrocyte function in vivo. The strategies used to obtain the different models include pharmacological modulation, injection of viral vectors for genetic manipulation, and/or the generation of genetically modified animals. The need for increased specificity in the brain region, cell type, or mechanism targeted has triggered in recent years the use of more-refined transgenic models. This has been achieved by (i) choosing specific astrocytic promoters (e.g., aldehyde dehydrogenase 1L1, Aldh1L1) [31-33], and (ii) the expression of machinery that allows inducible changes in gene expression. The latter include the tetracycline-controlled transcriptional activation and Cre/loxP recombination systems which allow temporal control of modulation, thus avoiding simultaneous compensatory mechanisms [22,23,34,35]. Importantly, the use of the Cre/loxP system expressed from different astrocyte-specific promoters has revealed that recombination has regional particularities. Therefore, careful characterization of functional alterations and reporter expression should be performed to confirm the suitability of a model for testing $[23,36]$. Future development of more specific probes, for example the CRISPR/Cas system (that allows easier and efficient modification of endogenous genes [37]), employed in specific brain areas and targeting specific spatiotemporal aspects of astrocyte activity, will further our understanding.

\section{Astrocytes influence the outputs generated by neuron- astrocyte networks}

In accordance with many available animal models described in Table 1, the current literature includes a large number of studies aimed at evaluating the consequences of in vivo manipulation of astrocyte function on animal behavior (Table 2). Generally, in this work researchers have performed behavioral analysis that compares experimental with control groups to estimate the effect of manipulation of the astrocytic component (see Box 1 for details). Complementary electrophysiology or imaging has been added in some cases. In this section we separately focus on studies of cognition, emotion, motor, and sensory functions.

\section{Cognition}

Cognition encompasses multiple functions including learning, memory, attention, and reasoning. Despite decades of research linking cognitive processing and fast synaptic transmission between connected neurons, cognitive output seems to also require complex integration of neuron-astrocyte networks in the temporal and spatial domains $[5,15]$. For example, incoming signals to astrocytes through cannabinoid receptor type 1 (CB1R) activation were shown to mediate resilience to spatial memory impairment and hippocampal long-term depression caused by cannabinoids
[38]. Moreover, the absence of gliotransmitter release, specifically in astrocytes, or blockade of adenosine A1 receptor, affected neuronal plasticity and cortical oscillations, and promoted resilience to the sleep pressure and spatial long-term memory impairments caused by sleep deprivation [39-42]. Accordingly, the same approach was also shown to avoid lipopolysaccharide-induced sleep pressure [43].

These results suggest that hippocampal astrocytes mediate negative outputs under adverse conditions. Indeed, the generation of interleukin 1 receptor (IL-1R)-expressing astrocytes in the hippocampus rescued the characteristic phenotype of IL-1R full knockout mice, namely severe memory disturbances in contextual fear conditioning and spatial reference memory (hippocampus-dependent), and in vivo long-term potentiation of hippocampal synapses, disclosing a role for astrocyte IL-1 signaling in this region [44].

Given the above, it is interesting that the enhanced production of the gliotransmitter D-serine by overexpression of serine racemase in astrocytes did not alter memory processing in mice [45]. Moreover, under physiological conditions, the alternative blockade of astrocyte vesicular release in mice that produce the botulinum neurotoxin type B specifically in glutamate/aspartate transporter (GLAST)-positive cells did not trigger any alterations in spatial memory tests, although here the authors claimed that the recombination in the hippocampus was not sufficient ([46]; discussed in [35,36]). The level and extent of gene recombination, protein expression, and subcellular localization is a very sensitive issue that requires careful consideration when establishing conclusions from experiments using transgenic animals (see [5]). Indeed, in contrast to the results reported in [46], the expression of clostridial toxin (tetanus neurotoxin, TeNT) specifically in astrocytes to block astrocyte calcium-dependent vesicular release was shown recently to cause a decrease in cortical gamma power that correlated with a key impairment in long-term recognition memory [47]. In addition, the activation of Gs-protein-coupled receptor was shown to be crucial for working memory, but deleterious for memory consolidation $[48,49]$. Curiously, the increase or ablation of astrocyte Gq-protein-dependent calcium signaling failed to affect hippocampal neuronal activity, synaptic plasticity [50-52], or spatial memory [53]. However, numerous studies have demonstrated the involvement of astrocyte signaling in synaptic plasticity in different brain areas and through different regulatory mechanisms (Table 3). These contrasting results cannot be accounted for solely by the existence of multiple forms of synaptic plasticity generated by diverse mechanisms, and therefore highlight the importance of the experimental paradigms used to stimulate neurons and astrocytes (discussed in [5]). For example, Tanaka and colleagues found that mice in which astrocyte calcium-signaling was inhibited presented memory deficits in hippocampus-dependent long-term memory tasks [54], suggesting that astrocytes may interfere with memory processing by means of alternative calcium-dependent mechanisms. Supporting this idea, blockade of glycogen breakdown by astrocytes, inhibiting the lactate shuttle to neurons, severely impaired long-term and working memory in rats $[55,56]$. 
Table 1. Animal models used to study astrocyte function in vivo

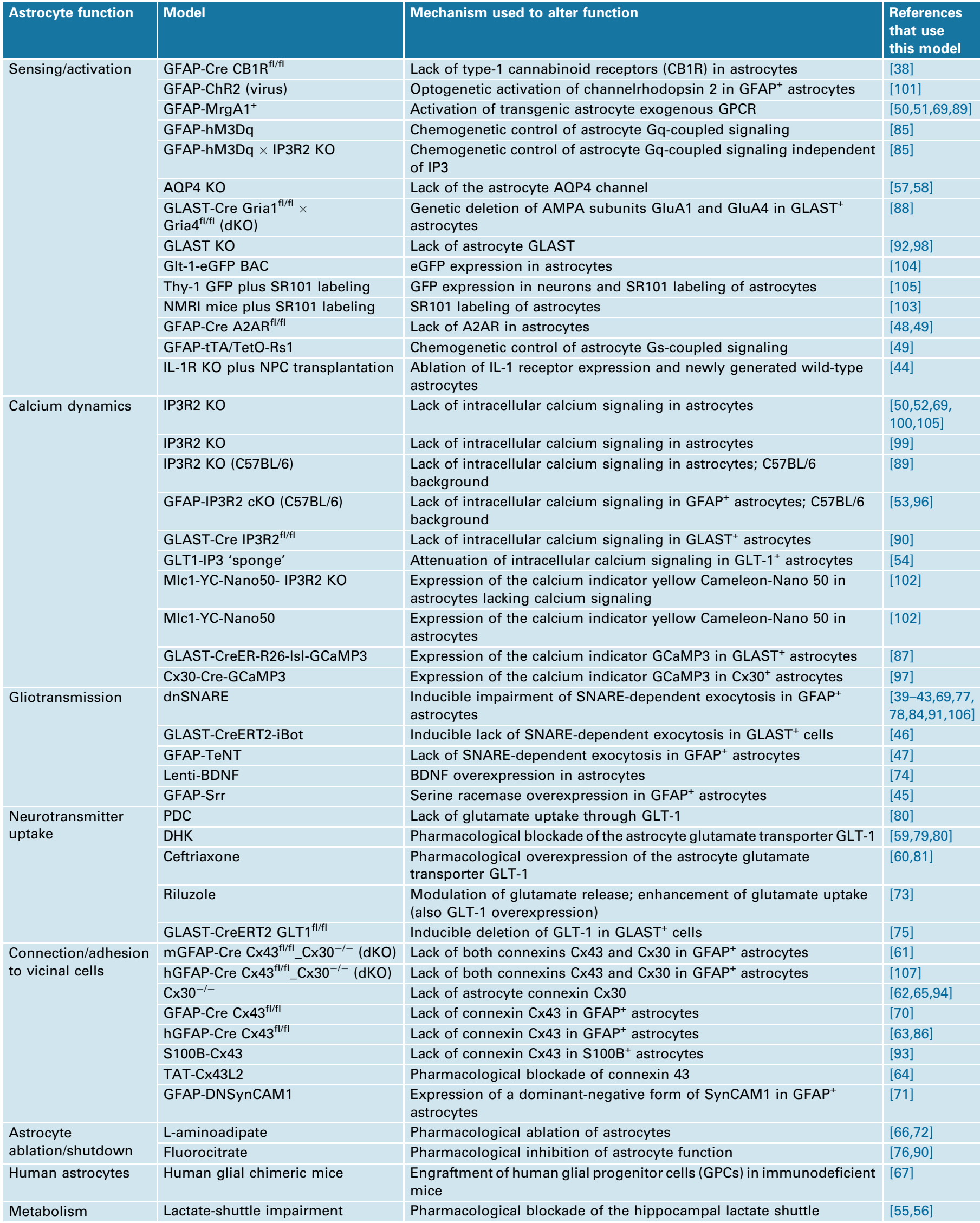


Table 2. In vivo outputs of animal models of astrocyte modulation ${ }^{\text {a }}$

\begin{tabular}{|c|c|c|c|c|}
\hline Model & Alteration/modulation & Approach & Phenotype & Refs \\
\hline \multicolumn{5}{|l|}{ Cognition } \\
\hline & $\begin{array}{l}\text { Lack of type-1 cannabinoid } \\
\text { receptors (CB1R) in astrocytes }\end{array}$ & In vivo electrophysiology & $\begin{array}{l}\uparrow \text { Resilience to CB-induced } \\
\text { hippocampal LTD; }\end{array}$ & [38] \\
\hline \multirow[t]{4}{*}{ dnSNARE } & \multirow{4}{*}{$\begin{array}{l}\text { Impairment of SNARE- } \\
\text { dependent exocytosis in GFAP } \\
\text { astrocytes }\end{array}$} & Brain slice electrophysiology & $\begin{array}{l}\downarrow \text { Hippocampal synaptic } \\
\text { plasticity }\end{array}$ & [42] \\
\hline & & Novel object recognition & $\begin{array}{l}\uparrow \text { Resilience to SD-induced long- } \\
\text { term memory impairment }\end{array}$ & [41] \\
\hline & & Contextual fear conditioning & $=$ Contextual fear memory & [41] \\
\hline & & Spatial object recognition & $\begin{array}{l}\uparrow \text { Resilience to SD-induced long- } \\
\text { term memory impairment }\end{array}$ & [40] \\
\hline $\begin{array}{l}\text { IL-1R KO plus NPC } \\
\text { transplantation }\end{array}$ & $\begin{array}{l}\text { Ablation of IL-1 receptor } \\
\text { expression plus newly } \\
\text { generated WT astrocytes }\end{array}$ & In vivo electrophysiology & $\begin{array}{l}\uparrow \text { Rescue of IL-1R KO LTP } \\
\text { impairment }\end{array}$ & [44] \\
\hline \multirow[t]{3}{*}{ GFAP-Srr } & \multirow{3}{*}{$\begin{array}{l}\text { Serine racemase } \\
\text { overexpression in } \mathrm{GFAP}^{+} \\
\text {astrocytes }\end{array}$} & $\begin{array}{l}\text { Y-maze spontaneous } \\
\text { alternation test }\end{array}$ & = Spatial working memory & [45] \\
\hline & & $\begin{array}{l}\text { Spatial reference memory } \\
\text { (MWM) }\end{array}$ & $=$ Long-term memory & [45] \\
\hline & & Operant Learning & $=$ Long-term memory & [45] \\
\hline \multirow[t]{2}{*}{ Glast-CreERT2-iBot } & \multirow[t]{2}{*}{$\begin{array}{l}\text { Lack of SNARE-dependent } \\
\text { exocytosis in } \text { GLAST }^{+} \text {cells }\end{array}$} & Novel object recognition & $\begin{array}{l}\text { = Short-term recognition } \\
\text { memory }\end{array}$ & {$[46]$} \\
\hline & & $\begin{array}{l}\text { Spatial reference memory } \\
\text { (MWM) }\end{array}$ & $=$ Long-term spatial memory & {$[46]$} \\
\hline GFAP-Cre $A 2 A R^{f l / f l}$ & Lack of A2AR in astrocytes & Contextual memory & $\uparrow$ Long-term memory & [49] \\
\hline GFAP-tTA-TetO-Rs 1 & $\begin{array}{l}\text { Chemogenetic control of } \\
\text { astrocyte Gs-coupled signaling }\end{array}$ & $\begin{array}{l}\text { Spatial reference memory } \\
\text { (MWM) }\end{array}$ & $\downarrow$ Long-term memory & [49] \\
\hline IP3R2 KO & $\begin{array}{l}\text { Lack of intracellular calcium } \\
\text { signaling in astrocytes }\end{array}$ & Brain slice electrophysiology & $\begin{array}{l}\text { = Hippocampal spontaneous/ } \\
\text { evoked activity; } \\
\text { = synaptic plasticity; }\end{array}$ & {$[50,52]$} \\
\hline GFAP-MrgA $1^{+}$ & $\begin{array}{l}\text { Activation of transgenic } \\
\text { astrocyte exogenous GPCR }\end{array}$ & Brain slice electrophysiology & $\begin{array}{l}\text { = Hippocampal spontaneous/ } \\
\text { evoked activity } \\
\text { = Synaptic plasticity }\end{array}$ & {$[50,51]$} \\
\hline GFAP-IP3R2 cKO (C57BL/6) & $\begin{array}{l}\text { Lack of intracellular calcium } \\
\text { signaling in GFAP }{ }^{+} \text {astrocytes; } \\
\text { C57BL/6 background; }\end{array}$ & $\begin{array}{l}\text { Spatial reference memory and } \\
\text { reversal learning (MWM) }\end{array}$ & $\begin{array}{l}=\text { Long-term spatial memory } \\
=\text { Reversal learning }\end{array}$ & [53] \\
\hline GLT1-IP3 'sponge' & $\begin{array}{l}\text { Attenuation of intracellular } \\
\text { calcium signaling in } \mathrm{GLT}-1^{+} \\
\text {astrocytes }\end{array}$ & $\begin{array}{l}\text { Spatial reference memory } \\
\text { (MWM) and fear conditioning }\end{array}$ & $\downarrow$ Long-term memory & {$[54]$} \\
\hline \multirow[t]{3}{*}{ Lactate-shuttle impairment } & \multirow{3}{*}{$\begin{array}{l}\text { Pharmacological blockade of } \\
\text { the hippocampal lactate shuttle }\end{array}$} & Inhibitory avoidance test & $\downarrow$ Long-term memory & [56] \\
\hline & & In vivo electrophysiology & $\downarrow$ Hippocampal LTP & {$[56]$} \\
\hline & & Spontaneous alternation task & $\begin{array}{l}\downarrow \text { Spatial working memory, } \\
\text { reverted by lactate or glucose } \\
\text { administration }\end{array}$ & [55] \\
\hline \multirow[t]{3}{*}{ AQP4 KO } & \multirow[t]{3}{*}{$\begin{array}{l}\text { Lack of the astrocyte AQP4 } \\
\text { channel }\end{array}$} & Fear conditioning & $\begin{array}{l}\downarrow \text { Long-term memory; rescue by } \\
\text { increasing GLT- } 1 \text { expression }\end{array}$ & [57] \\
\hline & & Fear conditioning & $=$ Long-term memory & [58] \\
\hline & & Spatial object recognition & $\downarrow$ Short-term memory & [58] \\
\hline
\end{tabular}


Table 2 (Continued)

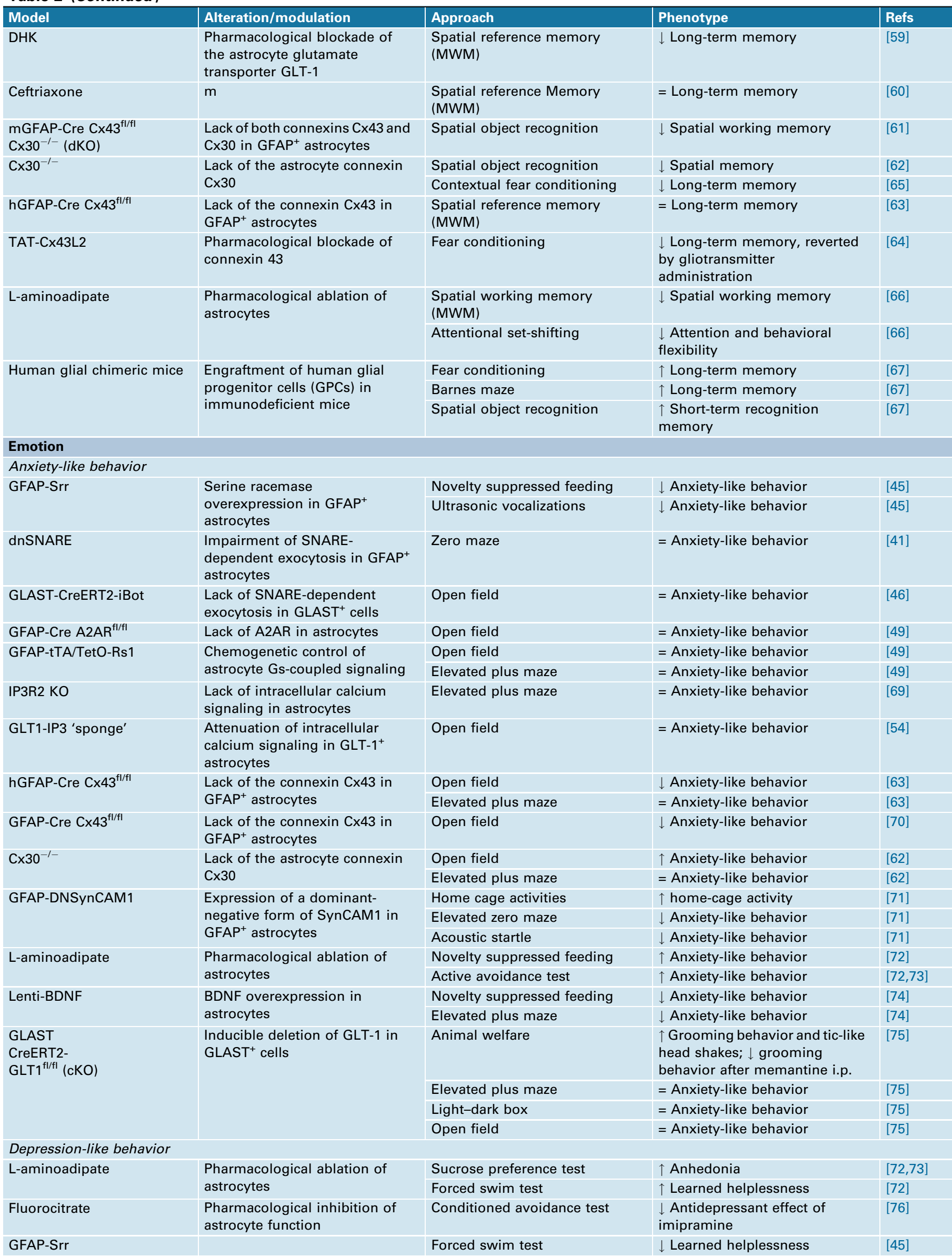


Table 2 (Continued)

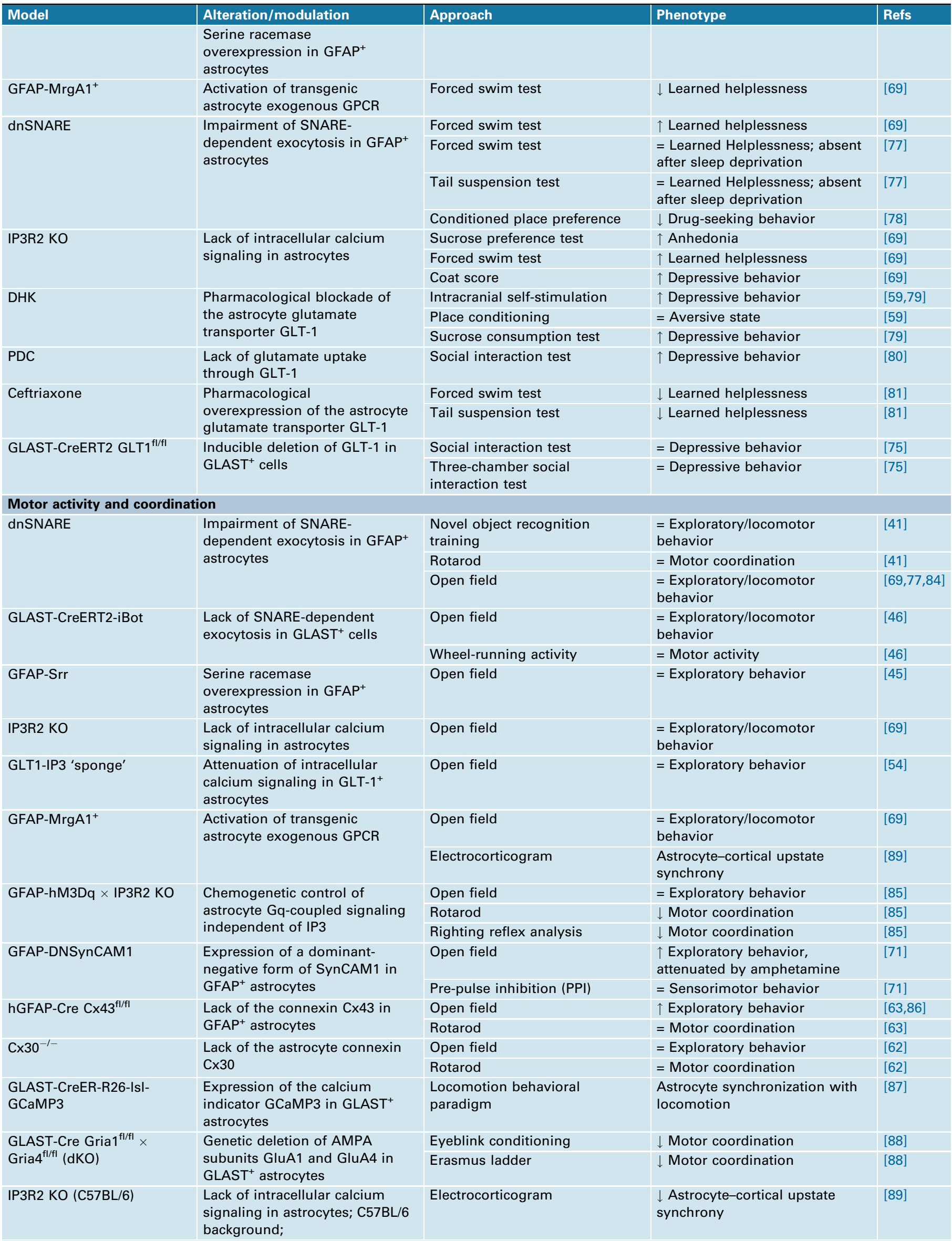


Table 2 (Continued)

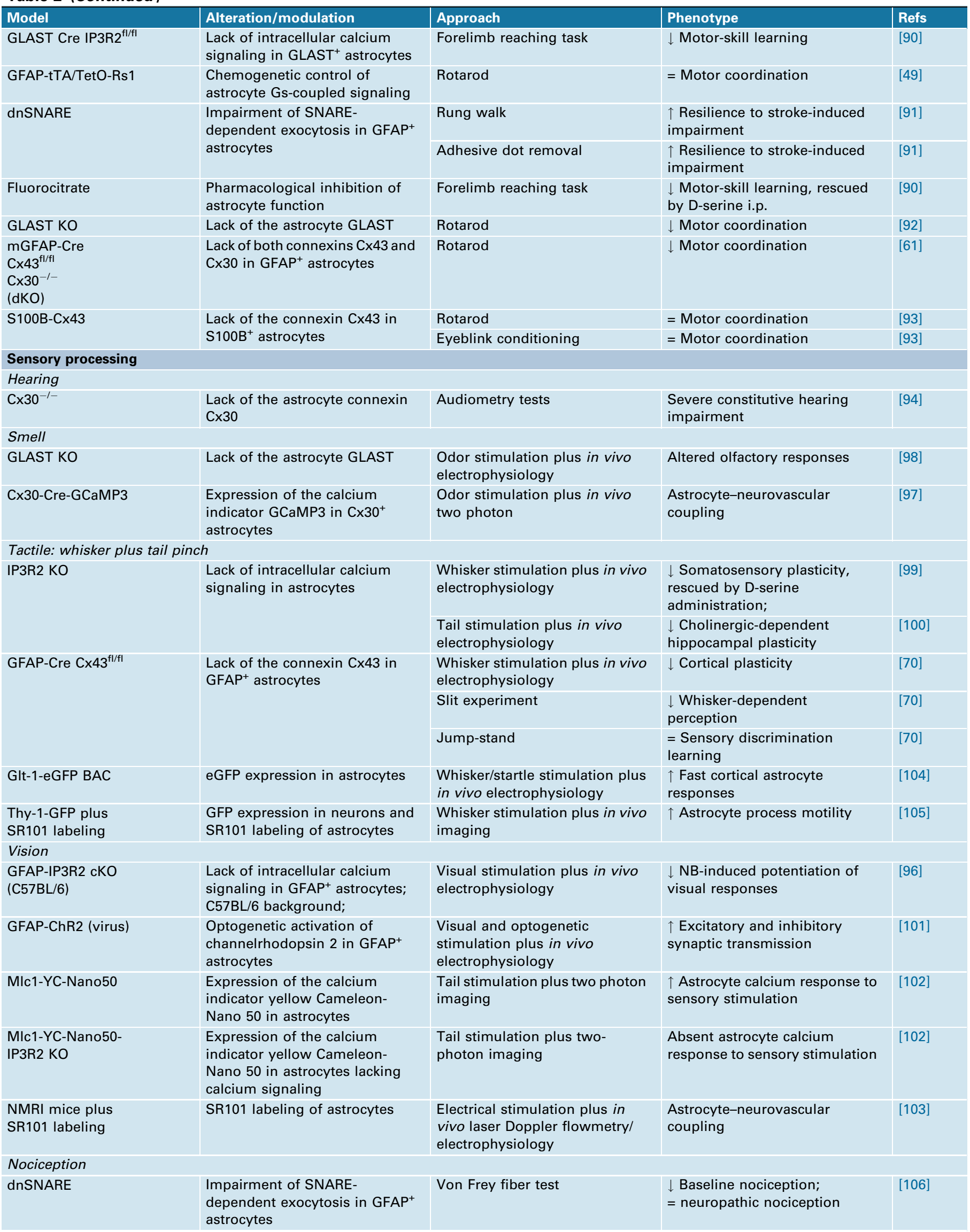


Table 2 (Continued)

\begin{tabular}{|c|c|c|c|c|}
\hline Model & Alteration/modulation & Approach & Phenotype & Refs \\
\hline $\begin{array}{l}\text { hGFAP-Cre } \\
\mathrm{C} \times 43^{\mathrm{fl} / \mathrm{fl}} \\
\mathrm{C} \times 30^{-1-} \\
(\mathrm{dKO})\end{array}$ & $\begin{array}{l}\text { Lack of both connexins } \mathrm{Cx} 43 \text { and } \\
\mathrm{C} \times 30 \text { in } \mathrm{GFAP}^{+} \text {astrocytes }\end{array}$ & Von Frey fiber test & $\downarrow$ SCl-triggered neuropathic pain & [107] \\
\hline \multirow[t]{2}{*}{$\mathrm{C} \times 30 \mathrm{KO}$} & \multirow[t]{2}{*}{$\begin{array}{l}\text { Lack of the astrocyte connexin } \\
\text { Cx30 }\end{array}$} & Von Frey fiber test & $\begin{array}{l}=\mathrm{SCl} \text {-triggered neuropathic } \\
\text { pain }\end{array}$ & [107] \\
\hline & & Plantar test & $\begin{array}{l}=\mathrm{SCl} \text {-triggered neuropathic } \\
\text { pain }\end{array}$ & [107] \\
\hline GFAP-tTA/TetO-Rs1 & $\begin{array}{l}\text { Chemogenetic control of } \\
\text { astrocyte Gs-coupled signaling }\end{array}$ & Hot plate test & $=$ Nociception & [49] \\
\hline \multirow{2}{*}{$\begin{array}{l}\text { Human glial } \\
\text { chimeric mice }\end{array}$} & \multirow{2}{*}{$\begin{array}{l}\text { Engraftment of human glial } \\
\text { progenitor cells (GPCs) in } \\
\text { immunodeficient mice }\end{array}$} & Von Frey fiber test & = Nociception & [67] \\
\hline & & Plantar test & $=$ Nociception & [67] \\
\hline
\end{tabular}

Recent evidence also suggests a role for aquaporin-4 channels in the modulation of network outputs. Mice lacking this channel were shown to display differently spatial or fear memory impairments, which may be justified by specific regional correlates $[57,58]$. In particular, the decrease in long-term fear memory correlated with a marked decrease in the expression of glutamate transporter GLT-1 in the amygdala, and was reverted by ceftriaxone administration that triggered GLT-1 expression in this region [57]. Interestingly, pharmacological blockade of GLT-1 was shown to induce by itself a decrease in spatial memory [59], whereas the administration of ceftriaxone in basal conditions did not alter spatial memory performance [60]. Together, these data suggest that continuous glutamate buffering is essential for neuron-astrocyte network activity.

Astrocyte coupling was also suggested as an alternative mechanism of cognitive modulation. Astrocyte circuits built up through gap junctions based on connexins Cx30 (gap junction protein $\beta 6, \mathrm{Gjb6}$ ) and $\mathrm{Cx} 43$ (gap junction protein $\alpha 1$, Gja1) enable rapid intercellular exchange of ions, metabolites, and neuroactive substances between astrocytes, thus allowing selective spatial communication. Mice lacking both astrocyte connexins [glial fibrillary acidic protein (GFAP)-Cre $\mathrm{Cx} 43^{\mathrm{f} / / \mathrm{fl}} \mathrm{Cx} 30^{-/-}$double knockout] have impaired spatial memory [61], a pattern also observed for the single knockout $\mathrm{Cx} 30^{-/-}$mice [62], but not for the GFAP-Cre $\mathrm{Cx} 43^{\mathrm{A} / \mathrm{fl}}$ mice [63]. More recently, specific antagonism of $\mathrm{Cx} 43$ was shown to trigger a longterm fear memory impairment that was rescued by gliotransmitter replacement [64]. Accordingly, $\mathrm{Cx} 30^{-/-}$mice were shown to display severe contextual fear conditioning memory impairment [65], confirming a crucial role of astrocyte coupling based on $\mathrm{Cx} 30$ for neuron-astrocyte network function.

While the deletion of specific astrocyte mechanisms seems to impair aspects of cognitive processing, it also seems to be true that astrocytes as a whole are crucial for network function. The specific ablation of astrocytes in the prefrontal cortex of rats is by itself responsible for a key impairment of reversal learning and working memory, tasks that are highly dependent on this brain region [66]. Accordingly, mice engrafted with human glia (about $20 \times$ larger and more complex than those of mice) in the hippocampus display enhanced learning abilities in tasks dependent on this region [67].

It is clear that interfering with astrocytes or astrocytic pathways causes consequences at the level of neuronal communication (measured by electrophysiological readouts), translated ultimately into behavioral outputs.

\section{Emotion}

Emotions are complex states of feeling that have been described as discrete and consistent responses to internal or external events. Emotional states result in physical and psychological changes that influence our behavior [68].

Regarding anxiety-like behavior, the increased availability of astrocyte D-serine leads to a less-anxious phenotype [45]. However, exocytotic release [41,46], Gsprotein-coupled receptor activation [49], and astrocyte IP3 signaling $[54,69]$ do not seem to interfere with the anxious state. Interestingly, a lack of physical communication through $\mathrm{Cx} 43[63,70]$ or synaptic adhesion molecule SynCAM1/CADM1 [71] appears to induce a less-anxious state. On the other hand, the ablation of $\mathrm{Cx} 30$ induces anxiety-like behavior [62]. Of note, the antagonistic effects displayed by mice lacking $\mathrm{Cx} 43$ or $\mathrm{Cx} 30$ were visible in the open-field arena, but were not confirmed in the elevated plus maze, a gold-standard test for anxiety-like behavior. Therefore, this effect needs further clarification using additional paradigms to assess anxiety. The pharmacological ablation of astrocytes in the prefrontal cortex was shown to induce anxious behavior per se [72,73], and brain-derived neurotrophic factor (BDNF) overexpression in hippocampal astrocytes produced an anxiolytic-like effect [74]. However, blockade of astrocyte glutamate uptake did not alter the anxiety phenotype, but triggered obsessive/compulsive-like behavior [75].

Together these data suggest that astrocytes are important for the anxiety balance and that astrocyte activation may represent a possible therapeutic target for the treatment of anxiety. 


\section{Box 1. Behavioral tests used to analyze astrocyte involvement in brain function}

Ultimately the outputs of the neuron-astrocyte network are translated in the form of behavior. We present in Table I an overview of the behavior tests used by researchers to analyze the impact of astrocytes on network function in the main behavioral dimensions.

Table I. Behavioral tests to analyze astrocyte involvement in brain function

\begin{tabular}{|c|c|c|c|}
\hline Test & Task & Function tested & Refs \\
\hline \multicolumn{4}{|l|}{ Cognition } \\
\hline Morris water maze & $\begin{array}{l}\text { Learn to escape to a hidden platform in a pool guided } \\
\text { by spatial cues. }\end{array}$ & $\begin{array}{l}\text { Spatial reference memory; } \\
\text { spatial working memory; cued } \\
\text { learning; spatial reversal } \\
\text { learning }\end{array}$ & $\begin{array}{l}{[38,44-46,54,} \\
58-60,63,66]\end{array}$ \\
\hline Radial arm maze & Explore the arms that contain a reward. & $\begin{array}{l}\text { Spatial working memory; } \\
\text { reference memory }\end{array}$ & [48] \\
\hline Barnes maze & Locate a hidden escape box on an open platform. & $\begin{array}{l}\text { Spatial reference memory; } \\
\text { spatial working memory }\end{array}$ & [67] \\
\hline Attentional set-shifting task & $\begin{array}{l}\text { Select a baited bowl by its odor or texture for food } \\
\text { reward. }\end{array}$ & $\begin{array}{l}\text { Non-spatial working memory: } \\
\text { attentional set-shifting and } \\
\text { reversal learning functions }\end{array}$ & [66] \\
\hline Novel object recognition & Explore a familiar and a novel object in an arena. & $\begin{array}{l}\text { Working memory; 'pure' } \\
\text { recognition memory test }\end{array}$ & {$[41,46,47,62]$} \\
\hline Object placement & $\begin{array}{l}\text { Explore two identical objects in the training day, } \\
\text { recognize relocated object on test day. }\end{array}$ & Spatial learning and memory & [58] \\
\hline $\begin{array}{l}\text { Jump-stand sensory- } \\
\text { discrimination learning }\end{array}$ & $\begin{array}{l}\text { Stretch across a gap to palpate textured surfaces with } \\
\text { vibrissae. }\end{array}$ & $\begin{array}{l}\text { Exploratory and discriminative } \\
\text { behavior; sensory learning }\end{array}$ & [70] \\
\hline T-maze & Explore a T-maze apparatus and enter the goal arm. & Spatial working memory & [38] \\
\hline Spontaneous alternation task & Explore the maze freely during $5 \mathrm{~min}$. & Spatial working memory & {$[45,47,48,55]$} \\
\hline Spatial object recognition task & Explore two different objects in an arena. & Spatial working memory & {$[40,61,67]$} \\
\hline Fear-conditioning paradigm & $\begin{array}{l}\text { Recognize that a novel environment is associated with } \\
\text { exposure to an aversive stimulus. }\end{array}$ & $\begin{array}{l}\text { Fear/emotion-based learning } \\
\text { and memory }\end{array}$ & $\begin{array}{l}{[44,47,54,57} \\
58,64,65,67,71\end{array}$ \\
\hline Inhibitory avoidance & $\begin{array}{l}\text { Explore a small starting compartment or a small } \\
\text { platform and receive a single footshock after entering a } \\
\text { larger compartment or stepping down from the } \\
\text { platform. }\end{array}$ & $\begin{array}{l}\text { Fear-motivated instrumental } \\
\text { learning }\end{array}$ & [56] \\
\hline
\end{tabular}

\section{Emotion}

Elevated plus maze

Elevated zero maze

Open field

Light-dark box

Slit experiment

Social interaction task (Crawley's)

Social interaction test Home-cage activity tests

Graded anxiety test Sucrose preference test

\section{Sucrose intake}

Novelty suppressed

feeding test

Forced swim test

Tail suspension test

Splash test

Two-way active avoidance test

Two-way conditioned avoidance test
Explore an apparatus with four arms (two open and two closed).

Explore an apparatus with two open and two enclosed elevated arms that form a zero or circle.

Explore an open and brightly illuminated square arena.

Explore an open field arena divided into two areas: dark and light.

Explore an apparatus that is divided into two areas (dark and light) by a baffle with holes of different sizes. Interact with familiar VS novel mouse in a threechamber arena.

Evaluate the interaction between two animals in a box. Monitor animals in their home cage environment.

Explore an adapted elevated-plus maze apparatus.

Evaluate the preference for sucrose solution or plain water during a determined period.

Intake of sucrose from two sucrose drinking bottles.

Reach a pellet placed in the center of the arena.

Swim in cylinders filled with water where there is no possible escape.

Struggle to face upward and climb to a solid surface where there is no possible escape.

Measure the latency until the animal starts grooming the dorsal coat sprayed with $10 \%$ sucrose.

Explore a box where the animals are exposed to stimulus and shocks.

Explore an apparatus where animals are exposed to a conditioned stimulus tone followed by electric shocks.

\section{Anxiety-like behavior \\ $[38,54,57,63$ \\ $69,74,75]$ \\ Anxiety-like behavior \\ [71] \\ Exploratory behavior and general activity \\ $[45,46,54,57$ $62,63,69-71$ $75,85,86,93]$ \\ [75] \\ anxiety-like behavior \\ Whisker-related exploratory \\ behavior \\ Social interaction \\ [70] \\ Social interaction \\ $[67,75]$ \\ Basic motor and sensory \\ $[75,80]$ \\ function \\ High-discriminative anxiety test [62] \\ Anhedonia/depression \\ $[69,72]$ \\ Anhedonia/depression \\ [79] \\ Anxiety-like behavior \\ $[45,72,74,81]$}

Depression-like behavior

$[45,69,72,81]$

Depression-like behavior

Depression-like and apathetic behavior

Anxiety-like behavior

Anxiety-like behavior 
Table I (Continued)

\begin{tabular}{|c|c|c|c|}
\hline Test & Task & Function tested & Refs \\
\hline $\begin{array}{l}\text { Prepulse inhibition of } \\
\text { startle reflex }\end{array}$ & $\begin{array}{l}\text { Exposure to a low intensity stimulus (prepulse) } \\
\text { followed by a test stimulus of a higher intensity. }\end{array}$ & Anxiety-like behavior & [71] \\
\hline Acoustic startle & $\begin{array}{l}\text { Exposure to different acoustic stimuli elicits a body } \\
\text { startle response. }\end{array}$ & Anxiety-like behavior & {$[71]$} \\
\hline Coat score assay & $\begin{array}{l}\text { Classify the coat state of the animal in seven different } \\
\text { parts of the body. }\end{array}$ & $\begin{array}{l}\text { Measure of stress-induced } \\
\text { behavioral effects }\end{array}$ & {$[69]$} \\
\hline $\begin{array}{l}\text { Grooming and tic-like } \\
\text { behavior }\end{array}$ & $\begin{array}{l}\text { Record the time spent in grooming and the tic-like } \\
\text { movements in a novel and familiar environment. }\end{array}$ & Grooming behavior & [75] \\
\hline $\begin{array}{l}\text { Conditioned } \\
\text { place-preference } \\
\text { paradigm }\end{array}$ & $\begin{array}{l}\text { Explore two identical chambers, designated as drug- } \\
\text { paired compartment and as vehicle-paired } \\
\text { compartment. }\end{array}$ & Reward/addiction & {$[59,78]$} \\
\hline $\begin{array}{l}\text { Operant drug/food } \\
\text { self-administration }\end{array}$ & Press the lever with reward delivery. & Reward/addiction & {$[45,78]$} \\
\hline $\begin{array}{l}\text { Ultrasonic vocalization } \\
\text { test }\end{array}$ & $\begin{array}{l}\text { Record and quantify ultrasonic vocalizations in } \\
\text { different frequencies. }\end{array}$ & $\begin{array}{l}\text { Anxiety-like behavior; } \\
\text { motivation; social interaction }\end{array}$ & [45] \\
\hline \multicolumn{4}{|c|}{ Motor activity and coordination } \\
\hline Locomotor activity & Explore a maze/home cage. & Motor function & {$[38,59,78]$} \\
\hline Motor balance & $\begin{array}{l}\text { Evaluate the ability to stay on a bar fixed horizontally } \\
\text { (max for } 10 \mathrm{~s} \text { ). }\end{array}$ & Motor balance & {$[38]$} \\
\hline Rotarod & Try to stay on the rotating cylinder without falling. & $\begin{array}{l}\text { Balance, grip strength, and } \\
\text { motor coordination }\end{array}$ & $\begin{array}{l}{[61-63,71} \\
85,92,93]\end{array}$ \\
\hline Balance beam assay & $\begin{array}{l}\text { Traverse a graded series of narrow beams to reach an } \\
\text { enclosed safety platform. }\end{array}$ & Motor coordination and balance & [61] \\
\hline Actimetry & $\begin{array}{l}\text { Evaluate the activity of animals (movement, } \\
\text { immobility, wheel-running activity) during light/dark } \\
\text { cycles. }\end{array}$ & $\begin{array}{l}\text { Motor function and } \\
\text { coordination }\end{array}$ & {$[46,72]$} \\
\hline $\begin{array}{l}\text { Loss of righting } \\
\text { reflex }\end{array}$ & $\begin{array}{l}\text { Right itself when placed on its back in a V-shaped } \\
\text { trough after administration of a drug. }\end{array}$ & Sedative/hypnotic state & [85] \\
\hline Rung walk & $\begin{array}{l}\text { Walk along a horizontal ladder with randomly spaced } \\
\text { rungs. }\end{array}$ & Motor function & [91] \\
\hline $\begin{array}{l}\text { Locomotor } \\
\text { behavioral paradigm }\end{array}$ & $\begin{array}{l}\text { Walk in a treadmill (freely movable/controlled by } \\
\text { motor) with the head immobilized. }\end{array}$ & Motor function & [87] \\
\hline Erasmus ladder & $\begin{array}{l}\text { Run on a horizontal ladder composed of sensitive rungs } \\
\text { with pressure sensors. }\end{array}$ & Motor coordination & {$[88]$} \\
\hline Forelimb reaching task & $\begin{array}{l}\text { Learn to reach through the slit with the preferred } \\
\text { forelimb and grasp to retrieve a pellet. }\end{array}$ & Motor-skill learning & {$[90]$} \\
\hline Eyeblink conditioning & $\begin{array}{l}\text { Exposure to an auditory or visual stimulus (the } \\
\text { conditioned stimulus), paired with an eyeblink-eliciting } \\
\text { unconditioned stimulus. }\end{array}$ & Motor learning & {$[88,93]$} \\
\hline \multicolumn{4}{|l|}{ Sensory processing } \\
\hline Footshock sensitivity test & $\begin{array}{l}\text { Respond to electrical shocks (intensity ranging } \\
\text { between } 0.05 \text { and } 1 \mathrm{~mA} \text { ). }\end{array}$ & Nociception & {$[54,57]$} \\
\hline Adhesive dot removal & $\begin{array}{l}\text { Detect and remove pieces of adhesive paper from their } \\
\text { wrists. }\end{array}$ & Sensorimotor function & {$[79,91]$} \\
\hline Von Frey fiber test & $\begin{array}{l}\text { Stimulate the hind limb by Von Frey monofilaments } \\
\text { until the animal removes its paw or maximal force is } \\
\text { reached. }\end{array}$ & Mechanical nociception & {$[67,106,107]$} \\
\hline Plantar test & Stimulate the hindpaw under a controlled heat source. & Thermal nociception & {$[67,107]$} \\
\hline Hot plate test & Place the footpad in contact with a heated surface. & Thermal nociception & {$[49,75]$} \\
\hline
\end{tabular}

Regarding effects of astrocyte modulation on mood, astrocyte ablation induced learned helplessness and anhedonia, widely accepted hallmarks of depressive-like behavior in rats [72,73], and the anti-depressant effect of imipramine was absent in a model of depression induced by blocking astrocyte metabolism [76]. Accordingly, the enhanced availability of astrocyte D-serine led to a reduced depressive phenotype [45]. Moreover, it was shown that specific activation of astrocytes through the Mas-related gene A1 receptor (MrgA1R) seems to follow the tendency observed for the anxiety state in this model and trigger a less-depressive phenotype [69]. Both effects seem to be mediated by astrocyte mechanisms because gliotransmission and inositol 1,4,5-trisphosphate receptor type 2 (IP3R2)-dependent signaling were shown to be crucial for both mood hallmarks [69] (although these data could not be confirmed in a different laboratory using two different tests to assess learned helplessness [77]). To clarify the role of gliotransmission, these effects should be carefully confirmed.

The inducible dominant-negative SNARE (dnSNARE; SNARE from 'soluble NSF attachment protein receptor') model allowed the demonstration that adenosine derived from astrocyte ATP mediates the learned helplessness caused by sleep deprivation [77], and that gliotransmission is necessary for reinstatement of drug-seeking behaviors 


\begin{tabular}{|c|c|c|c|}
\hline Brain area & Stimuli & Gliotransmitter & Refs \\
\hline \multirow[t]{8}{*}{ Hippocampus } & Endogenous & ATP & [42] \\
\hline & Calcium uncaging & Glutamate & [109] \\
\hline & Depolarization & Glutamate & [110] \\
\hline & Endogenous & D-serine & [111] \\
\hline & Glutamate & ATP & [112] \\
\hline & Acetylcholine & Glutamate & [100] \\
\hline & Cannabinoids & Glutamate & [38] \\
\hline & Endocannabinoids & Glutamate & [113] \\
\hline \multirow[t]{2}{*}{ Cortex } & Acetylcholine & D-serine & [99] \\
\hline & Endocannabinoids & Glutamate & [114] \\
\hline $\begin{array}{l}\text { Supraoptic } \\
\text { nucleus }\end{array}$ & Endogenous & D-serine & {$[115]$} \\
\hline
\end{tabular}

by cocaine or associated cues [78]. Accordingly, pharmacological blockade of astrocyte glutamate buffering by blockade of the astrocyte GLT-1 glutamate transporter triggered depressive-like behavior in the form of increase of intracranial self-stimulation, latency to drink sucrose solution [59,79], or decrease in social interaction [80]. Moreover, the chronic administration of ceftriaxone, that leads to the overexpression of GLT-1, was shown to produce a reduction in learned helplessness [81]; however, its deletion in GLAST ${ }^{+}$cells did not affect depressive behavior [75]. These data provide some hints that support a link between astrocyte function and the modulation of depressive behavior, but further work will be needed to clarify the extent of modulation and the mechanisms involved.

\section{Motor activity and coordination}

Assessment of motor performance is of great relevance when evaluating behavior in animal models, and each novel model should be carefully characterized for this dimension. Motor activity is obviously important for research on sensorimotor function; however, it might have broader behavioral implications (e.g., if an animal with normal learning capabilities has motor deficits it will have difficulties to reach a platform in the Morris water maze, leading to false results). Therefore, behavioral experiments intended to assess other dimensions (e.g., cognition or emotion) should always be interpreted with combined assessment of sensorimotor function. Furthermore, many paradigms used to test behavior in rodent models are based in the observation that rodents have a high exploratory drive. In fact, the analysis of spontaneous exploratory behavior is of great importance because it provides a simple and direct measure of motor function and emotional state, and alterations in exploratory behavior may condition the analysis of additional phenotypic parameters (e.g., cognitive tasks) $[82,83,119]$.

Exploratory activity was shown to be unaltered in mice in which gliotransmitter release $[41,45,46,69,77,84]$ or intracellular calcium elevations are impaired [54,69]. The activation of Gq-protein-coupled MrgA1 receptors expressed specifically in astrocytes also failed to interfere with exploratory behavior [69]. However, mice expressing alternative Gq-protein-coupled hM3Dq in astrocytes displayed alteration of the exploratory pattern in a longer protocol, an effect that was independent of inositol trisphosphate (IP3) signaling [85]. Curiously, astrocytic coupling seems to interfere differentially with exploratory behavior. The conditional ablation of $\mathrm{Cx} 43$ or of adhesion molecule SynCAM1 in astrocytes seems to enhance exploration $[63,71,86]$, while the full ablation of Cx30 does not has an impact on the horizontal exploratory drive [62]. These data might suggest that astrocyte mechanisms do not interfere with general exploratory behavior, but investigations in tests of longer duration are required.

Motor function was shown to induce activation of astrocyte networks in multiple brain regions through concerted norepinephrine signaling [87], suggesting a role for astrocytes in the integration of motor information. In addition to adrenergic input, glutamatergic signaling through AMPA receptor activation in the cerebellum was shown to support fine motor coordination [88]. By contrast, astrocyte Gqprotein-coupled receptor activation led to impairment of motor coordination that was independent of the IP3R2 [85], although it was also shown to cause IP3R2-dependent astrocyte calcium increase and consequent Purkinje cell activation [89]. Accordingly, IP3R2-dependent astrocyte calcium was also shown to enhance motor skill learning [90]. Curiously, activation of Gs-protein-coupled receptors in astrocytes did not interfere with motor coordination [49].

Regarding the impact of gliotransmitter release on motor function, its conditional blockade does not seem to interfere with motor coordination [41,46], but offered resilience to stroke-triggered motor impairment [91]. Interestingly, D-serine administration can rescue fluorocitrateinduced inactivation of astrocyte function in a motor skill-learning task [90]. The absence of GLAST leads to impaired motor coordination [92], probably due to cerebellar excitotoxicity. In addition, astrocyte coupling through $\mathrm{Cx} 43$, but not through $\mathrm{Cx} 30$, was shown to be specifically important for correct motor coordination [61-63]. Curiously, the effect of $\mathrm{Cx} 43$ ablation in $\mathrm{GFAP}^{+}$cells was not observed in mice that lack CX43 in $\mathrm{S}^{+} 00 \beta^{+}$cerebellar astrocytes and Bergmann glia [93], and this may support the hypothesis that astrocytes expressing different markers also perform different functions.

\section{Sensory processing}

Complementary to motor performance, sensory function is of great importance for appropriate evaluation of behavior. A sensory impairment might bias interpretation of experimental results (e.g., if an animal with normal learning capabilities has visual deficits it will face a difficulty in following external cues to reach a platform in the Morris water maze, leading to false results). Hence, sensory abilities should be assessed for all animal models [82,83,119].

Regarding the basic sensory functions, Cx30 knockout mice were reported to have a severe hearing impairment [94]. In addition, IP3R2 knockout mice generated on a Black Swiss background may display retinal degeneration, leading to performance deficits in cognitive tests [95], which may be reverted (for instance, by backcrossing the line with C57BL/6 mice $[53,89,96])$. Although blockade of exocytosis in astrocytes altered the function of Müller cells in the retina, the visual abilities of these mice remained unaffected [46]. Regarding the role of astrocytes in odor 
processing, it has been shown that astrocytes respond with fast calcium elevations to odor stimulation [97], and that the lack of astrocyte transporter GLAST led to misprocessing of odor inputs that was ascribed to alterations in gamma oscillations [98].

Sensory stimulation was shown to potentiate cortical responses when paired with electrical stimulation in the nucleus basalis of Meynert (NBM), the primary cholinergic input to the cerebral cortex. This effect was absent in mice lacking astrocyte calcium signaling, although it was rescued by D-serine administration in these animals [99]. Accordingly, cortical plasticity triggered by whisker stimulation alone was abolished by deleting $\mathrm{Cx} 43$, which translated to a severe impairment of whisker-dependent tactile function [70]. Similarly, astrocyte calcium signaling was shown to be crucial for cholinergic dependent plasticity in the hippocampus [100] and for NBM-induced potentiation of visual responses [96]. These results indicate an important role of astrocytes in the processing of cholinergic input in corticolimbic circuits. More recently, an elegant study in which optogenetic tools were used to specifically activate $\mathrm{GFAP}^{+}$astrocytes demonstrated that this activation is responsible for both excitatory and inhibitory synaptic transmission in the primary visual cortex [101]. In addition, different studies have reported that sensory stimulation triggers fast calcium transients in astrocytes [102], coupled with hemodynamic responses in the same brain region [103]. These fast signals were also observed in the locus coeruleus after whisker air-puff startle stimulation; this has implications for the effects of adrenergic projections to cortical areas [104]. Finally, similar sensory stimulation triggered astrocyte process motility and calcium signals, which correlated with enhanced synaptic plasticity [105].

Lastly, astrocytes seem to interfere with pain processing because impairment of astrocyte exocytosis in the dnSNARE animals reduced baseline mechanical nociception, although nociception during neuropathic pain was unaltered [106], and astrocyte-specific deletion of $\mathrm{Cx} 43$ prevented the development of chronic neuropathic pain following spinal cord injury [107]. These results suggest a clear involvement of astrocytes in nociceptive processing by brain networks, but the involvement appears to be very specific because Gs-coupled protein activation of astrocytes, blockade of glutamate uptake, or engraftment of human astrocytes failed to interfere with nociception $[49,67,75]$.

\section{Conceptual challenges and future perspectives}

The evidence obtained thus far points to important roles played by astrocytes in network computation of behavioral outputs in the four main behavioral dimensions discussed in this review (summarized in Figure 1). It is clear that the

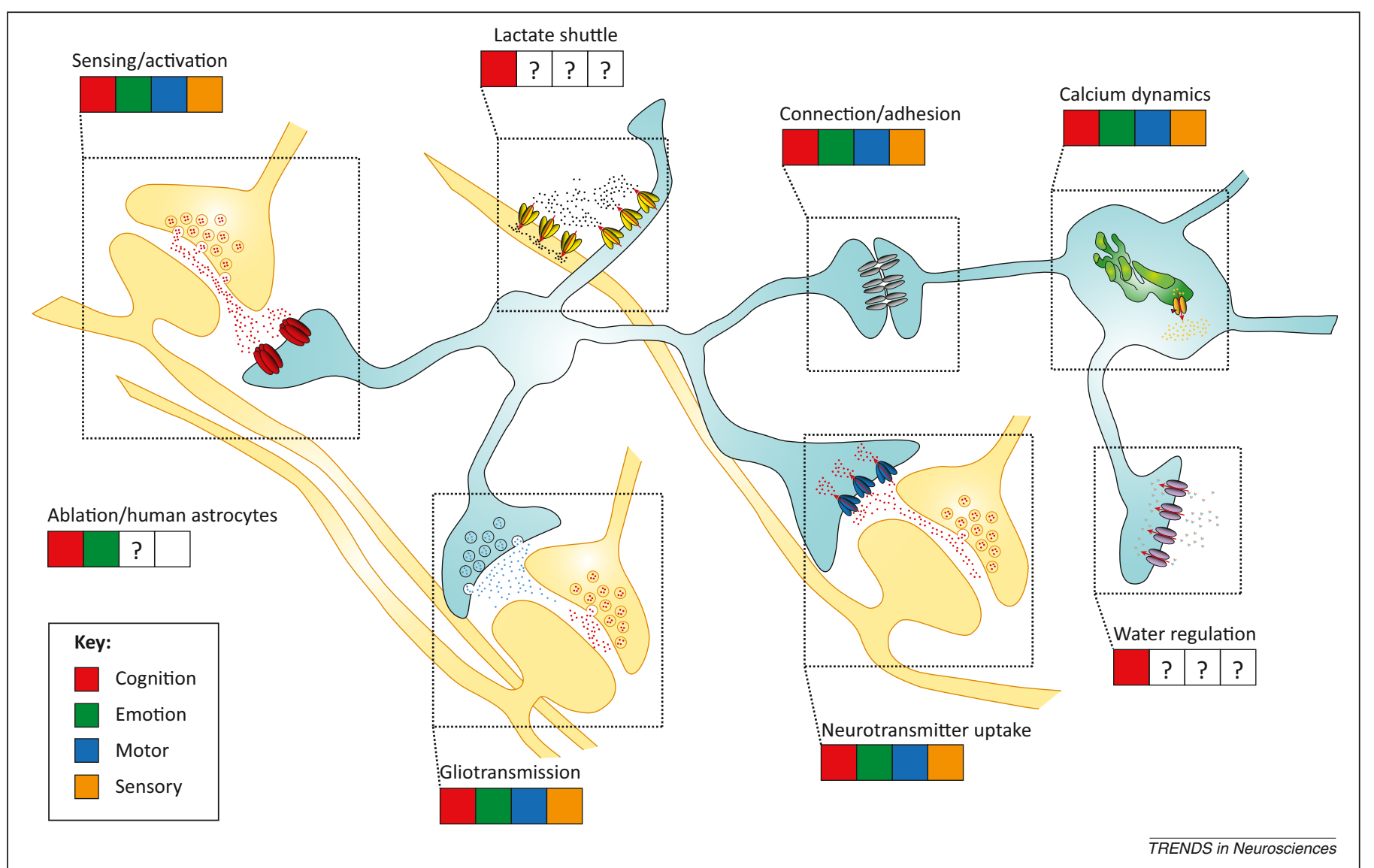

Figure 1. Behavioral dimensions affected by different astrocytic functions. The scheme represents the behavioral dimensions affected after modulation of each astrocytic function. Each frame with four squares represents the behavioral dimensions, from left to right: cognition (red); emotion (green); motor activity and coordination (blue); sensory processing (orange). A colored square indicates that at least one study has implicated astrocytes in that particular behavioral dimension. White squares refer to dimensions not affected by astrocyte modulation, while question marks identify dimensions that are yet to be assessed. Figure elements: neurons (yellow); astrocytes (blue). Depicted structures: G-protein-coupled receptors (red); lactate transporters (yellow); glutamate transporters (blue); aquaporin channels (purple); connexins/adhesion molecules (grey); inositol trisphosphate (IP3) receptors (orange). Molecules: neurotransmitters (red dots); gliotransmitters (blue dots); lactate (black dots); water (red/blue dots); IP3 (orange). Arrows (red) indicate the direction of the net molecule movement. 
dialog between astrocytes and neurons is crucial for correct performance of the neuron-astrocyte network in all the behavioral domains analyzed. One should note, however, that although we know now that a given astrocyte function is important for network performance, these observations are still very general because the functions studied include general astrocyte mechanisms (e.g., exocytosis or calcium dynamics), and usually across extensive brain areas (e.g., in whole-brain receptor knockouts). It is also noteworthy that, for each function, the results differed both across different models and even within the same model. These discrepancies must be explained by further studies (Box 2).

The establishment of the contribution of astrocytes to behavior faces important experimental and conceptual challenges that derive from the relatively initial stages of our knowledge on the specific properties of astrocyte physiology and astrocyte-neuron communication. For example, astrocytes are emerging as a more heterogeneous cell type than was previously thought $[108,120]$. Regional heterogeneity as well as cellular subtype specificity within brain areas need to be considered when modulating

\section{Box 2. Outstanding questions}

\section{How might model diversity affect my results?}

- The first concern is related to the inherent divergence of available models. For instance, there are at least five different IP3R2 KO strains. The generation of different strains arises from the consensual need for a consistent genetic background and cellular specificity. However, researchers should take this compilation into account and try to focus on common strains for better integration of the data obtained.

- The second concern is that new (and perhaps also existing) models should be fully validated. The molecular mechanisms underlying the genetic manipulation are crucial for the interpretation of data. For example, the use of $\mathrm{Cre} / \mathrm{loxP}$ recombination or tetracycline-inducible mice should be characterized in detail because they may lead to unexpected outcomes, such as lack of recombination, regional specificities, or even unspecific transgene expression $[36,116]$, that will require further clarification and confirmation for each model in each laboratory [49].

Which aspects shall we take into consideration when interpreting the data available so far and in preparing future in vivo studies?

- Phenotypes of animal models of astrocyte dysfunction should be carefully characterized because impairments in basic processing such as motor or sensory functions may lead to false results by, for instance, affecting the performance of cognitive tasks.

- Behavioral testing should be addressed and analyzed very carefully, preferably using standard protocols to permit better comparison between different studies, and different behavioral paradigms to assess a similar function (e.g., the Morris water maze and the radial arm maze to assess spatial reference memory).

- The analysis of brain outputs should include complementary techniques such as behavioral analysis, in vivo electrophysiology, and imaging to obtain valuable and consistent information; the approaches used should evolve to address (i) the temporal and spatial resolution characteristic of astrocyte somata and fine processes $[117,118]$, and (ii) the direct impact of astrocytes on calcium oscillations or electrophysiological signals rather than an indirect neuronal readout.

- Classically, different tasks rely on specific networks (e.g., spatial memory relies on the dorsal hippocampus) whose neurons display characteristic anatomical and functional features; similarly, the apparent molecular, cellular, and functional heterogeneity presented by astrocytes $[108,120]$ may lead to an unexpected diversity of effects and needs careful interpretation. astrocytes to evaluate their consequences on animal behavior (Box 2). Moreover, astrocyte control of behavior will include long-range spatial and temporal integration of information, and this adds an extra layer of complexity, putatively providing the network with increased degrees of freedom to perform a given task [5].

In summary, accumulating evidence indicates a direct involvement of astrocyte function in animal behavior, based on the key properties of astrocyte function in regulating neuronal and synaptic function through the control of brain homeostasis, neuronal metabolism, and gliotransmission. It is our belief that future research should be guided by innovation in the design of more-accurate models and techniques and, most importantly, by the adequate selection of the best option for in vivo analysis taking into account the functional heterogeneity of astrocytes.

\section{Acknowledgments}

The authors acknowledge funding from the Marie Curie Fellowship FP7PEOPLE-2010-IEF 273936 and BIAL Foundation Grant 61/2010 to J.F.O.; Foundation for Science and Technology (FCT) project grant (PTDC/SAU-NSC/118194/2010) to J.F.O., V.M.S., and S.G.G.; and fellowships (SFRH/BD/89714/2012 to V.M.S., SFRH/BPD/97281/2013 to J.F.O. and SFRH/BD/101298/2014 to S.G.G.); Human Frontier Science Program (Research Grant RGP0036/2014) to A.A.; FEDER funds through the Operational Program for Competitiveness Factors (COMPETE), and 'ON2 Programa Operacional Regional do Norte (ON.2 O Novo Norte)' QREN/FEDER to N.S.

\section{References}

1 Cornell-Bell, A.H. et al. (1990) Glutamate induces calcium waves in cultured astrocytes: long-range glial signaling. Science 247, 470-473

2 Nedergaard, M. (1994) Direct signaling from astrocytes to neurons in cultures of mammalian brain cells. Science 263, 1768-1771

3 Parpura, V. et al. (1994) Glutamate-mediated astrocyte-neuron signalling. Nature 369, 744-747

4 Allen, N.J. and Barres, B.A. (2009) Neuroscience: glia-more than just brain glue. Nature 457, 675-677

5 Araque, A. et al. (2014) Gliotransmitters travel in time and space. Neuron 81, 728-739

6 Clarke, L.E. and Barres, B.A. (2013) Emerging roles of astrocytes in neural circuit development. Nat. Rev. Neurosci. 14, 311-321

7 Halassa, M.M. and Haydon, P.G. (2010) Integrated brain circuits: astrocytic networks modulate neuronal activity and behavior. Annu. Rev. Physiol. 72, 335-355

8 Kimelberg, H.K. and Nedergaard, M. (2010) Functions of astrocytes and their potential as therapeutic targets. Neurotherapeutics 7, 338-353

9 Paixão, S. and Klein, R. (2010) Neuron-astrocyte communication and synaptic plasticity. Curr. Opin. Neurobiol. 20, 466-473

10 Pannasch, U. and Rouach, N. (2013) Emerging role for astroglial networks in information processing: from synapse to behavior. Trends Neurosci. 36, 405-417

11 Parpura, V. and Verkhratsky, A. (2012) Homeostatic function of astrocytes: $\mathrm{Ca}^{2+}$ and $\mathrm{Na}^{+}$signalling. Transl. Neurosci. 3, 334-344

12 Perea, G. et al. (2009) Tripartite synapses: astrocytes process and control synaptic information. Trends Neurosci. 32, 421-431

13 Wang, D. and Bordey, A. (2008) The astrocyte odyssey. Prog. Neurobiol. 86, 342-367

14 Araque, A. et al. (1999) Tripartite synapses: glia, the unacknowledged partner. Trends Neurosci. 22, 208-215

15 Fields, R.D. et al. (2014) Glial biology in learning and cognition. Neuroscientist 20, 426-431

16 Perea, G. et al. (2014) Neuron-glia networks: integral gear of brain function. Front. Cell. Neurosci. 8, 378

17 Hirase, H. et al. (2014) Volume transmission signalling via astrocytes. Philos. Trans. R. Soc. Lond. B: Biol. Sci. 369, 20130604

18 Rusakov, D.A. et al. (2014) Diversity of astroglial functions alludes to subcellular specialisation. Trends Neurosci. 37, 228-242 
19 Volterra, A. et al. (2014) Astrocyte $\mathrm{Ca}^{2+}$ signalling: an unexpected complexity. Nat. Rev. Neurosci. 15, 327-335

20 Haydon, P.G. and Nedergaard, M. (2015) How do astrocytes participate in neural plasticity? Cold Spring Harb. Perspect. Biol. 7, a020438

21 Krügel, U. et al. (2013) Integration of neuronal and glial signalling by pyramidal cells of the rat prefrontal cortex; control of cognitive functions and addictive behaviour by purinergic mechanisms. $J$. Hung. Assoc. Psychopharmacol. 15, 206-213

22 Davila, D. et al. (2013) Recent molecular approaches to understanding astrocyte function in vivo. Front. Cell. Neurosci. 7, 272

$23 \mathrm{Li}, \mathrm{D}$. et al. (2013) New tools for investigating astrocyte-to-neuron communication. Front. Cell. Neurosci. 7, 193

24 Xie, A.X. et al. (2015) Molecular approaches for manipulating astrocytic signaling in vivo. Front. Cell. Neurosci. 9, 144

25 Nimmerjahn, A. and Bergles, D.E. (2015) Large-scale recording of astrocyte activity. Curr. Opin. Neurobiol. 32, 95-106

26 Nedergaard, M. et al. (2010) Glial calcium and diseases of the nervous system. Cell Calcium 47, 140-149

27 Allaman, I. et al. (2011) Astrocyte-neuron metabolic relationships: for better and for worse. Trends Neurosci. 34, 76-87

28 Molofsky, A.V. et al. (2012) Astrocytes and disease: a neurodevelopmental perspective. Genes Dev. 26, 891-907

29 Jun, C. et al. (2014) Disturbance of the glutamatergic system in mood disorders. Exp. Neurobiol. 23, 28

30 Rossi, D. (2015) Astrocyte physiopathology: at the crossroads of intercellular networking, inflammation and cell death. Prog. Neurobiol. 130, 86-120

31 Cahoy, J.D. et al. (2008) A transcriptome database for astrocytes, neurons, and oligodendrocytes: a new resource for understanding brain development and function. J. Neurosci. 28, 264-278

32 Tien, A-C. et al. (2012) Regulated temporal-spatial astrocyte precursor cell proliferation involves BRAF signalling in mammalian spinal cord. Development 139, 2477-2487

33 Götz, M. et al. (2015) Reactive astrocytes as neural stem or progenitor cells: in vivo lineage, in vitro potential, and genome-wide expression analysis. Glia $63,1452-1468$

34 Casper, K.B. et al. (2007) Characterization of astrocyte-specific conditional knockouts. Genesis 45, 292-299

35 Pfrieger, F.W. and Slezak, M. (2012) Genetic approaches to study glial cells in the rodent brain. Glia 60,681-701

36 Slezak, M. et al. (2007) Transgenic mice for conditional gene manipulation in astroglial cells. Glia 55, 1565-1576

37 Sander, J.D. and Joung, J.K. (2014) CRISPR-Cas systems for editing, regulating and targeting genomes. Nat. Biotechnol. 32, 347-355

38 Han, J. et al. (2012) Acute cannabinoids impair working memory through astroglial CB1 receptor modulation of hippocampal LTD. Cell $148,1039-1050$

39 Fellin, T. et al. (2009) Endogenous nonneuronal modulators of synaptic transmission control cortical slow oscillations in vivo. Proc. Natl. Acad. Sci. U.S.A. 106, 15037-15042

40 Florian, C. et al. (2011) Astrocyte-derived adenosine and A1 receptor activity contribute to sleep loss-induced deficits in hippocampal synaptic plasticity and memory in mice. J. Neurosci. 31, 6956-6962

41 Halassa, M.M. et al. (2009) Astrocytic modulation of sleep homeostasis and cognitive consequences of sleep loss. Neuron 61, 213-219

42 Pascual, O. et al. (2005) Astrocytic purinergic signaling coordinates synaptic networks. Science 310, 113-116

43 Nadjar, A. et al. (2013) Astrocyte-derived adenosine modulates increased sleep pressure during inflammatory response. Glia 61, $724-731$

44 Ben Menachem-Zidon, O. et al. (2011) Astrocytes support hippocampal-dependent memory and long-term potentiation via interleukin-1 signaling. Brain Behav. Immun. 25, 1008-1016

45 Otte, D-M. et al. (2013) Effects of chronic D-serine elevation on animal models of depression and anxiety-related behavior. PLOS ONE 8, e67131

46 Slezak, M. et al. (2012) Relevance of exocytotic glutamate release from retinal glia. Neuron 74, 504-516

47 Lee, H.S. et al. (2014) Astrocytes contribute to gamma oscillations and recognition memory. Proc. Natl. Acad. Sci. U.S.A. 111, E3343-E3352

48 Matos, M. et al. (2015) Deletion of adenosine A2A receptors from astrocytes disrupts glutamate homeostasis leading to psychomotor and cognitive impairment: relevance to schizophrenia. Biol. Psychiatry Published online February 28, 2015. http://dx.doi.org/ 10.1016/j.biopsych.2015.02.026

49 Orr, A.G. et al. (2015) Astrocytic adenosine receptor A2A and Gscoupled signaling regulate memory. Nat. Neurosci. 18, 423-434

50 Agulhon, C. et al. (2010) Hippocampal short- and long-term plasticity are not modulated by astrocyte $\mathrm{Ca}^{2+}$ signaling. Science 327, 1250-1254

51 Fiacco, T.A. et al. (2007) Selective stimulation of astrocyte calcium in situ does not affect neuronal excitatory synaptic activity. Neuron 54, 611-626

52 Petravicz, J. et al. (2008) Loss of IP3 receptor-dependent $\mathrm{Ca}^{2+}$ increases in hippocampal astrocytes does not affect baseline CA1 pyramidal neuron synaptic activity. J. Neurosci. 28, 4967-4973

53 Petravicz, J. et al. (2014) Astrocyte IP3R2-dependent $\mathrm{Ca}^{2+}$ signaling is not a major modulator of neuronal pathways governing behavior. Front. Behav. Neurosci. 8, 384

54 Tanaka, M. et al. (2013) Astrocytic $\mathrm{Ca}^{2+}$ signals are required for the functional integrity of tripartite synapses. Mol. Brain 6, 6

55 Newman, L.A. et al. (2011) Lactate produced by glycogenolysis in astrocytes regulates memory processing. PLoS ONE 6, e28427

56 Suzuki, A. et al. (2011) Astrocyte-neuron lactate transport is required for long-term memory formation. Cell 144, 810-823

$57 \mathrm{Li}$, Y-K. et al. (2012) Aquaporin-4 deficiency impairs synaptic plasticity and associative fear memory in the lateral amygdala: involvement of downregulation of glutamate transporter-1 expression. Neuropsychopharmacology 37, 1867-1878

58 Scharfman, H.E. and Binder, D.K. (2013) Aquaporin-4 water channels and synaptic plasticity in the hippocampus. Neurochem. Int. 63, 702711

59 Bechtholt-Gompf, A.J. et al. (2010) Blockade of astrocytic glutamate uptake in rats induces signs of anhedonia and impaired spatial memory. Neuropsychopharmacology 35, 2049-2059

60 Karaman, I. et al. (2013) Lack of effect of ceftriaxone, a GLT-1 transporter activator, on spatial memory in mice. Pharmacol. Biochem. Behav. 108, 61-65

61 Lutz, S.E. et al. (2009) Deletion of astrocyte connexins 43 and 30 leads to a dysmyelinating phenotype and hippocampal CA1 vacuolation. $J$. Neurosci. 29, 7743-7752

62 Dere, E. et al. (2003) Connexin30-deficient mice show increased emotionality and decreased rearing activity in the open-field along with neurochemical changes. Eur. J. Neurosci. 18, 629-638

63 Frisch, C. et al. (2003) Mice with astrocyte-directed inactivation of connexin 43 exhibit increased exploratory behaviour, impaired motor capacities, and changes in brain acetylcholine levels. Eur. J. Neurosci. 18, 2313-2318

64 Stehberg, J. et al. (2012) Release of gliotransmitters through astroglial connexin 43 hemichannels is necessary for fear memory consolidation in the basolateral amygdala. FASEB J. 26, 3649-3657

65 Pannasch, U. et al. (2014) Connexin 30 sets synaptic strength by controlling astroglial synapse invasion. Nat. Neurosci. 17, 549-558

66 Lima, A. et al. (2014) Astrocyte pathology in the prefrontal cortex impairs the cognitive function of rats. Mol. Psychiatry 19, 834-841

67 Han, X. et al. (2013) Forebrain engraftment by human glial progenitor cells enhances synaptic plasticity and learning in adult mice. Cell Stem Cell 12, 342-353

68 Fox, E. (2008) Emotion Science: Cognitive and Neuroscientific Approaches to Understanding Human Emotions, Palgrave Macmillan

69 Cao, X. et al. (2013) Astrocyte-derived ATP modulates depressive-like behaviors. Nat. Med. 19, 773-777

70 Han, Y. et al. (2014) Astrocyte-restricted disruption of connexin-43 impairs neuronal plasticity in mouse barrel cortex. Eur. J. Neurosci. 39, 35-45

71 Sandau, U.S. et al. (2012) Astrocyte-specific disruption of SynCAM1 signaling results in ADHD-like behavioral manifestations. PLOS ONE 7, e36424

72 Banasr, M. and Duman, R.S. (2008) Glial loss in the prefrontal cortex is sufficient to induce depressive-like behaviors. Biol. Psychiatry 64, 863-870

73 Banasr, M. et al. (2010) Glial pathology in an animal model of depression: reversal of stress-induced cellular, metabolic and behavioral deficits by the glutamate-modulating drug riluzole. Mol. Psychiatry 15, 501-511 
74 Quesseveur, G. et al. (2013) BDNF overexpression in mouse hippocampal astrocytes promotes local neurogenesis and elicits anxiolytic-like activities. Transl. Psychiatry 3, e253

75 Aida, T. et al. (2015) Astroglial glutamate transporter deficiency increases synaptic excitability and leads to pathological repetitive behaviors in mice. Neuropsychopharmacology 40, 1569-1579

76 Iwata, M. et al. (2011) Hippocampal astrocytes are necessary for antidepressant treatment of learned helplessness rats. Hippocampus 21, 877-884

77 Hines, D.J. et al. (2013) Antidepressant effects of sleep deprivation require astrocyte-dependent adenosine mediated signaling. Transl. Psychiatry 3, e212

78 Turner, J.R. et al. (2013) Cocaine-related behaviors in mice with deficient gliotransmission. Psychopharmacology (Berl.) 226, 167-176

79 John, C.S. et al. (2012) Blockade of astrocytic glutamate uptake in the prefrontal cortex induces anhedonia. Neuropsychopharmacology 37, 2467-2475

80 Lee, Y. et al. (2007) Glia mechanisms in mood regulation: a novel model of mood disorders. Psychopharmacology 191, 55-65

81 Mineur, Y.S. et al. (2007) Antidepressant-like effects of ceftriaxone in male C57BL/6J mice. Biol. Psychiatry 61, 250-252

82 Crawley, J.N. (2000) What's Wrong With my Mouse? Behavioral Phenotyping of Transgenic and Knockout Mice. Wiley-Liss

83 Sousa, N. et al. (2006) A hitchhiker's guide to behavioral analysis in laboratory rodents. Genes Brain Behav. 5, 5-24

84 Clasadonte, J. et al. (2013) Astrocyte control of synaptic NMDA receptors contributes to the progressive development of temporal lobe epilepsy. Proc. Natl. Acad. Sci. U.S.A. 110, 17540-17545

85 Agulhon, C. et al. (2013) Modulation of the autonomic nervous system and behaviour by acute glial cell Gq protein-coupled receptor activation in vivo. J. Physiol. 591, 5599-5609

86 Theis, M. et al. (2003) Accelerated hippocampal spreading depression and enhanced locomotory activity in mice with astrocyte-directed inactivation of connexin 43. J. Neurosci. 23, 766-776

87 Paukert, M. et al. (2014) Norepinephrine controls astroglial responsiveness to local circuit activity. Neuron 82, 1263-1270

88 Saab, A.S. et al. (2012) Bergmann glial AMPA receptors are required for fine motor coordination. Science 337, 749-753

89 Wang, F. et al. (2012) Bergmann glia modulate cerebellar Purkinje cell bistability via $\mathrm{Ca}^{2+}{ }_{-}$dependent $\mathrm{K}^{+}$uptake. Proc. Natl. Acad. Sci. U.S.A. 109, 7911-7916

90 Padmashri, R. et al. (2015) Motor-skill learning is dependent on astrocytic activity. Neural Plast. 2015, 938023

91 Hines, D.J. and Haydon, P.G. (2013) Inhibition of a SNARE-sensitive pathway in astrocytes attenuates damage following stroke. $J$. Neurosci. 33, 4234-4240

92 Watase, K. et al. (1998) Motor discoordination and increased susceptibility to cerebellar injury in GLAST mutant mice. Eur. J. Neurosci. 10, 976-988

93 Tanaka, M. (2008) Lack of connexin 43-mediated Bergmann glial gap junctional coupling does not affect cerebellar long-term depression, motor coordination, or eyeblink conditioning. Front. Behav. Neurosci. 2,1

94 Teubner, B. et al. (2003) Connexin 30 (Gjb6)-deficiency causes severe hearing impairment and lack of endocochlear potential. Hum. Mol. Genet. 12, 13-21

95 Clapcote, S.J. et al. (2005) NIH Swiss and Black Swiss mice have retinal degeneration and performance deficits in cognitive tests. Comp. Med. 55, 310-316

96 Chen, N. et al. (2012) Nucleus basalis-enabled stimulus-specific plasticity in the visual cortex is mediated by astrocytes. Proc. Natl. Acad. Sci. U.S.A. 109, E2832-E2841
97 Otsu, Y. et al. (2015) Calcium dynamics in astrocyte processes during neurovascular coupling. Nat. Neurosci. 18, 210-218

98 Martin, C. et al. (2012) Alteration of sensory-evoked metabolic and oscillatory activities in the olfactory bulb of GLAST-deficient mice. Front. Neural Circuits 6, 1

99 Takata, N. et al. (2011) Astrocyte calcium signaling transforms cholinergic modulation to cortical plasticity in vivo. J. Neurosci. 31, 18155-18165

100 Navarrete, M. et al. (2012) Astrocytes mediate in vivo cholinergicinduced synaptic plasticity. PLoS Biol. 10, e1001259

101 Perea, G. et al. (2014) Optogenetic astrocyte activation modulates response selectivity of visual cortex neurons in vivo. Nat. Commun. 5,3262

102 Kanemaru, K. et al. (2014) In vivo visualization of subtle, transient, and local activity of astrocytes using an ultrasensitive $\mathrm{Ca}^{2+}$ indicator. Cell Rep. 8, 311-318

103 Lind, B.L. et al. (2013) Rapid stimulus-evoked astrocyte $\mathrm{Ca}^{2+}$ elevations and hemodynamic responses in mouse somatosensory cortex in vivo. Proc. Natl. Acad. Sci. U.S.A. 110, E4678-E4687

104 Ding, F. et al. (2013) a1-Adrenergic receptors mediate coordinated $\mathrm{Ca}^{2+}$ signaling of cortical astrocytes in awake, behaving mice. Cell Calcium 54, 387-394

105 Perez-Alvarez, A. et al. (2014) Structural and functional plasticity of astrocyte processes and dendritic spine interactions. J. Neurosci. 34, 12738-12744

106 Foley, J.C. et al. (2011) Gliotransmission modulates baseline mechanical nociception. Mol. Pain 7, 93

107 Chen, M.J. et al. (2012) Astrocytic CX43 hemichannels and gap junctions play a crucial role in development of chronic neuropathic pain following spinal cord injury. Glia 60, 1660-1670

108 Khakh, B.S. and Sofroniew, M.V. (2015) Diversity of astrocyte functions and phenotypes in neural circuits. Nat. Neurosci. 18 942-952

109 Perea, G. and Araque, A. (2007) Astrocytes potentiate transmitter release at single hippocampal synapses. Science $317,1083-1086$

110 Jourdain, P. et al. (2007) Glutamate exocytosis from astrocytes controls synaptic strength. Nat. Neurosci. 10, 331-339

111 Henneberger, C. et al. (2010) Long-term potentiation depends on release of D-serine from astrocytes. Nature 463, 232-236

112 Panatier, A. et al. (2011) Astrocytes are endogenous regulators of basal transmission at central synapses. Cell 146, 785-798

113 Gomez-Gonzalo, M. et al. (2014) Endocannabinoids induce lateral long-term potentiation of transmitter release by stimulation of gliotransmission. Cereb. Cortex Published online September 26, 2014. http://dx.doi.org/10.1093/cercor/bhu231

114 Min, R. and Nevian, T. (2012) Astrocyte signaling controls spike timing-dependent depression at neocortical synapses. Nat. Neurosci. 15, 746-753

115 Panatier, A. et al. (2006) Glia-derived D-serine controls NMDA receptor activity and synaptic memory. Cell 125, 775-784

116 Fujita, T. et al. (2014) Neuronal transgene expression in dominantnegative SNARE Mice. J. Neurosci. 34, 16594-16604

117 Srinivasan, R. et al. (2015) $\mathrm{Ca}^{2+}$ signaling in astrocytes from Ip3r2 $2^{-/-}$ mice in brain slices and during startle responses in vivo. Nat. Neurosci. 18, 708-717

118 Khakh, B.S. and McCarthy, K.D. (2015) Astrocyte calcium signaling: from observations to functions and the challenges therein. Cold Spring Harb. Perspect. Biol. 7, a020404

119 Buccafusco, J.J. (2000) Methods of Behavior Analysis in Neuroscience, CRC Press

120 Martín, R. et al. (2015) Circuit-specific signaling in astrocyte-neuron networks in basal ganglia pathways. Science 349 , 730-734 